\title{
SISTEM PENUNJANG KEPUTUSAN PEMBAYARAN SUMBANGAN PEMBINAAN PENDIDIKAN DENGAN CICILAN PADA BIMBEL BINTANG CEMERLANG
}

\author{
Rika Juliyana $^{1}$, Desi Novianti ${ }^{2}$, Dwi Dani Apriyani ${ }^{3}$ \\ ${ }^{1,2,3}$ Program Studi Teknik Informatika, Universitas Indraprasta PGRI \\ Jalan Raya Tengah No 80, Kelurahan Gedong, Pasar Rebo, Jakarta Timur \\ rikajulliyana@gmail.com ${ }^{1}$, desi.novi4nti@gmail.com ${ }^{2}$, dwidani12@gmail.com ${ }^{3}$
}

\begin{abstract}
Abstrak
Bimbingan Belajar (Bimbel) adalah suatu bentuk bantuan untuk peserta didik agar mampu melakukan penyesuaian diri, membuat beberapa pilihan, memecahkan masalah-masalah pendidikan, pengajaran dan pembelajaran yang sedang dihadapinya. Untuk siswa yang ingin melakukan pembelajaran di bimbel, orang tua harus memenuhi pembayaran perbulannya. Maka munculah permasalahan dibimbel khususnya pada pembayaran, yaitu pendataan masih menggunakan manual yaitu tulis tangan di dalam buku besar, banyak orangtua siswa yang mengajukan pembayaran dengan menyicil sehingga pihak bimbel kesulitan menentukan siapa yang layak mendapat cicilan dan bimbel memberikan cicilan tanpa melihat kemampuan orang tua dan ekonomi yang mengakibatkan pemberian cicilan ke orang tua siswa tidak sesuai targetnya dan pembuatan laporan juga memerlukan banyak waktu karena harus mengecek buku besar dan rekapan. Sehingga tujuan dari penelitian ini adalah membuat sebuah sistem komputer yaitu untuk meringankan pekerjaan admin dalam pendataan admin, pendataan siswa, pendataan wali siswa, pendataan permohonan cicilan, menghitung proses penentuan kelayakan cicilan agar mendapat hasil yang lebih akurat dan pembuatan laporan dari prosesnya agar dapat menjadi lebih cepat dan tepat dimana metode pengambilan keputusan menggunakan SAW dan dirancang menggunakan flowchart. Sehingga didapatkan solusi untuk permasalahan di bimbel bintang cemerlang yaitu dengan membuat perhitungan kelayakan penerima cicilan dengan hasil yang akurat.
\end{abstract}

Kata Kunci : bimbel, cicilan, pembayaran, Simple Additive Weighting (SAW), SPK.

\begin{abstract}
Tutoring (Bimbel) is a form of assistance for students to be able to make adjustments, make several choices, solve educational, teaching and learning problems they are facing. For students who want to do lessons in tutoring, parents must meet the monthly payment. Then the problem arises in tutoring, especially in payments, namely data collection still uses manual, namely handwriting in a ledger, many parents apply for payments in installments so that tutors have difficulty determining who is eligible for installments and tutoring provides installments regardless of the ability of parents and the economy which resulted in giving installments to parents of students not according to the target and making reports also required a lot of time because they had to check ledgers and recaps. Judging from the problems mentioned above, the purpose of making a computer system is to ease the admin's work in admin data collection, student data collection, student guardian data collection, installment application data collection, calculating the process of determining installment eligibility in order to get more accurate results and making reports from the process so that can be faster and more precise where the method used in this system is the waterfall which is designed using a flowchart. So that the solution to the problems in the Bimbel Bintang Cemerlang is obtained, namely by calculating the eligibility of the installment recipient with accurate results.
\end{abstract}

Keyword : installments, payments, Simple Additive Weighting (SAW), SPK, tutoring.

\section{PENDAHULUAN}

Bimbingan Belajar (Bimbel) adalah suatu bentuk bantuan untuk peserta didik agar mampu melakukan penyesuaian diri, membuat beberapa pilihan, memecahkan masalah-masalah pendidikan, pengajaran dan pembelajaran yang sedang dihadapinya (Sihombing, 2021). Untuk siswa yang ingin melakukan pembelajaran di bimbel, orang tua harus memenuhi pembayaran perbulannya. Pembayaran yaitu sebuah transaksi yang dilakukan untuk memindahkan mata uang menjadi suatu jasa, barang atau informasi dari pembayar ke penerima, baik secara langsung maupun dengan jasa perbankan. (Prabowo \& Suyono, 2018). Sumbangan Pembinaan Pendidikan yang biasa disebut SPP yaitu pembayaran yang dilakukan dengan rutin yang harus dibayarkan oleh 
siswa, biasanya dana SPP tersebut diperoleh dari orangtua siswa atau wali siswa dimana pembayaran dilakukan setiap perbulan. Fungsi dari pembayaran SPP yaitu untuk mencukupi setiap anggaran biaya dan mendukung kegiatan pembelajaran siswa di bimbel. Dimana tujuan adanya pembayaran SPP yaitu untuk membiayai jasa, keperluan, fasilitas bimbel agar kegiatan belajar mengajar di bimbel dapat berjalan lancar (Prabowo \& Suyono, 2018).

Bimbingan Belajar Bintang Cemerlang merupakan sebuah instansi yang berada di Kecamatan Pasar Rebo Jakarta Timur. Jam mengajar pada Bimbel Bintang Cemerlang yaitu 2 jam dari hari senin sampai kamis. Pembayaran SPP di bimbel bintang cemerlang menggunakan sistem membayar bulanan. Dimana orang tua siswa datang ke bimbel untuk melakukan transaksi pembayaran dengan uang cash. Jika ada siswa yang menunggak, bimbel akan menyarankan untuk membayar dengan sistem menyicil.

Kondisi pembayaran yang berjalan saat ini masih tidak efektif yang menyebabkan timbulnya beberapa permasalahan dari pembayaran spp adalah pendataan terbilang masih memakai sistem manual yaitu dengan tertulis yang membutuhkan waktu lama dalam pencarian data dikarenakan banyaknya tumpukan buku dan banyak siswa yang mengalami penunggakan pembayaran SPP sehingga banyak orang tua siswa yang meminta pembayaran dengan menyicil menyebabkan pihak bimbel kesulitan dalam menentukan siapa saja yang layak mendapat cicilan sehingga pihak bimbel memberikan cicilan tanpa melihat kemampuan orang tua dan ekonomi yang berakibat pemberian cicilan ke orang tua siswa tidak sesuai targetnya. Pembuatan laporan juga memerlukan banyak waktu karena harus mengecek buku besar dan rekapan sehingga data yang dihasilkan tidak sesuai. Adapun tujuan yang ingin diraih dalam sistem ini yaitu meringankan pekerjaan admin dalam pendataan admin, pendataan siswa, pendataan wali siswa, pendataan permohonan cicilan, menghitung proses penentuan kelayakan cicilan dan pembuatan laporan dari prosesnya agar menjadi cepat, tepat dan akurat sehingga dapat bermanfaat bagi masyarakat yaitu diharapkannya penelitian ini menjadi bahan referensi untuk mahasiswa lain mengenai sistem penunjang keputusan agar dapat dipahami dan di pelajari sebaik mungkin serta memberikan rekomendasi, gambaran dan membantu mengambil keputusan dalam proses permohonan cicilan orang tua siswa pada Bimbel Bintang Cemerlang.

\section{PENELITIAN RELEVAN}

Penelitian Jurnal Teknovasi oleh Siti Aisyah yang berjudul Aplikasi Sistem Pendukung Keputusan Analisis Kelayakan Pemberian Kredit Menggunakan Metode SAW Pada Perusahaan Leasing (Siti Aisyah, 2019). Hasil dari penelitian ini adalah membantu proses penilaian kelayakan pemberian kredit dengan menggunakan metode $S A W$ yang berjalan dengan baik dan pengguna dapat menyesuaikan nilai crisp dan nilai bobot dari masing-masing kriteria serta kriteria kredit yang bermasalah di dalam aplikasi, sehingga proses penilaian dapat disesuaikan dengan kebutuhan. Penelitian Jurnal Journal Of Information Systems oleh Tri Hardiyanti yang berjudul Sistem Pendukung Keputusan untuk Menentukan Biaya Sumbangan Penyelenggaraan Pendidikan Siswa Baru dengan Menggunakan Metode Simple Additive Weighting pada SMK St. Fransiskus Semarang (Hardiyanti, 2016). Hasil dari penelitian ini adalah untuk menentukan biaya SPP siswa baru yang dihasilkan dapat membantu kerja tim sekolah sehingga informasi yang didapatkan bersifat akurat dan tepat waktu.

\section{METODE PENELITIAN}

\section{Desain Penelitian}

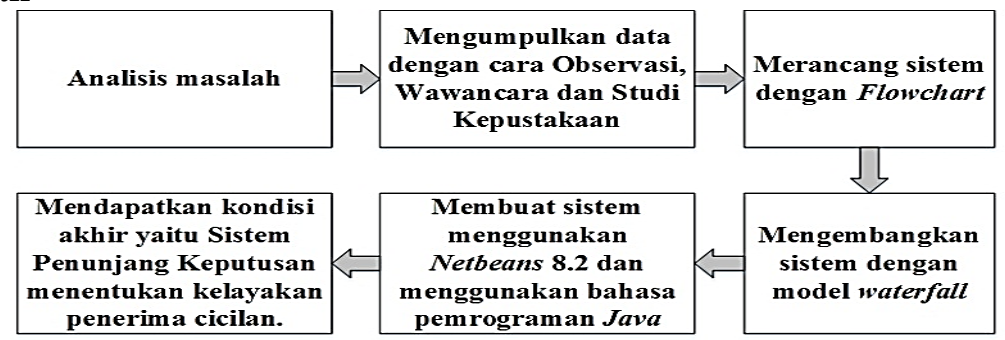

Gambar 1. Desain Penelitian 
Penulis menganalisis masalah yang ada pada bimbel dengan mengumpulkan data dengan observasi, wawancara dan melakukan studi kepustakaan, merancang sebuah sistem dengan flowchart dengan mengembangkan sistem dengan model waterfall dan mulai membuat sistem dengan menggunakan tools Netbeans 8.2 serta bahasa pemrograman java.

\section{Observasi}

Penulis melakukan observasi secara langsung dengan mempelajari dan mengamati sistem pembayaran yang terdapat di Bimbel Bintang Cemerlang.

Tabel 1. Observasi

\begin{tabular}{|c|l|l|}
\hline No & \multicolumn{1}{|c|}{ Masalah Yang Diamati } & \multicolumn{1}{c|}{ Solusi } \\
\hline 1. & $\begin{array}{l}\text { Dalam melakukan pendataan, admin masih } \\
\text { menggunakan sistem manual yaitu dengan tertulis } \\
\text { sehingga memerlukan waktu lama dalam } \\
\text { pembuatannya. }\end{array}$ & $\begin{array}{l}\text { Membuat sistem yang dapat mempercepat } \\
\text { pendataan sehingga tidak membutuhkan waktu } \\
\text { yang lama. }\end{array}$ \\
\hline 2. & $\begin{array}{l}\text { Dalam pembayaran, pihak bimbel memberikan cicilan } \\
\text { tanpa melihat kemampuan orang tua dan ekonomi } \\
\text { sehingga menyebabkan pemberian cicilan ke orang tua } \\
\text { siswa tidak sesuai targetnya. }\end{array}$ & $\begin{array}{l}\text { Membuat sistem untuk menentukan kelayakan } \\
\text { pemberian cicilan ke orang tua siswa }\end{array}$ \\
\hline 3. & $\begin{array}{l}\text { Proses pembuatan laporan memerlukan banyak waktu } \\
\text { karena harus mengecek buku besar sehingga data yang } \\
\text { dihasilkan tidak sesuai. }\end{array}$ & $\begin{array}{l}\text { Membuat sistem yang dapat membuat laporan } \\
\text { dengan cepat dan akurat }\end{array}$ \\
\hline
\end{tabular}

\section{Wawancara}

Penulis melakukan wawancara langsung kepada pemilik bimbel dan admin, Ibu Ayu Widowati untuk mendapatkan data informasi yang dibutuhkan.

\begin{tabular}{|c|l|l|}
\hline No & \multicolumn{1}{|c|}{ Masalah Yang Diamati } & \multicolumn{1}{c|}{ Tabel 2. Wawancara } \\
\hline 1. & $\begin{array}{l}\text { Bolehkah saya mengetahui sejarah } \\
\text { dari terbentuknya Bimbel Bintang } \\
\text { Cemerlang? }\end{array}$ & $\begin{array}{l}\text { Bimbel ini berdiri mulai tahun 2014, yang awalnya didirikan oleh 2 } \\
\text { orang lulusan Universitas Indraprasta PGRI dimana hanya 10 } \\
\text { murid yang belajar pada waktu itu. Seiring bertambahnya waktu, } \\
\text { bimbel ini mengalami kemajuan. Bertambahnya murid dan } \\
\text { meluasnya tempat belajar. }\end{array}$ \\
\hline 2. & $\begin{array}{l}\text { Berapa lama waktu yang diperlukan } \\
\text { untuk siswa belajar disini? }\end{array}$ & $\begin{array}{l}\text { Satu siswa belajar hanya 2 jam dari senin sampai kamis. Kami buka } \\
\text { dari jam 10 pagi sampai 5 sore. }\end{array}$ \\
\hline 4. & Bagaimana program kerja disini? & $\begin{array}{l}\text { Admin biasanya mendata siswa yang baru masuk ke bimbel } \\
\text { dengan menggunakan buku besar. Admin juga membuat laporan } \\
\text { dengan menulis di buku laporan untuk diberikan ke pimpinan. Jika } \\
\text { ada yang ingin membayar, siswa langsung mendatangi admin dan } \\
\text { akan langsung dibuatkan kwitansi. }\end{array}$ \\
\hline $5 . \quad \begin{array}{l}\text { Banyak siswa yang menunggak membayar SPP bulanan. Salah satu } \\
\text { faktor utama yaitu menurunna ekonomi keluarga. Jadi banyak } \\
\text { orang tua siswa yang meminta pembayaran dengan menyicil } \\
\text { menyebabkan pihak bimbel kesulitan dalam menentukan siapa saja } \\
\text { yang layak mendapat cicilan sehingga bimbel memberikan cicilan } \\
\text { anpa melihat kemampuan orang tua dan ekonomi yang berakibat } \\
\text { pemberian cicilan ke orang tua siswa tidak sesuai targetnya }\end{array}$ \\
\hline
\end{tabular}

\section{Analisa Permasalahan}

Untuk membuat sistem, penulis menganalisa kebutuhan user agar sistem dapat dipakai sesuai dengan kebutuhan.

Tabel 3. Analisa Kebutuhan User

\begin{tabular}{|c|c|c|c|}
\hline No. & User & Sistem Yang Berjalan & Solusi \\
\hline 1. & Admin & $\begin{array}{l}\text { 1. Pendataan masih menggunakan } \\
\text { sistem manual yaitu dengan tertulis } \\
\text { sehingga memerlukan waktu lama } \\
\text { dalam pembuatannya karena } \\
\text { menggunakan buku besar. } \\
\text { 2. Pembuatan laporan masih } \\
\text { memerlukan waktu yang cukup lama } \\
\text { karena harus mengecek buku besar } \\
\text { sehingga data yang dihasilkan sering } \\
\text { tidak sesuai. }\end{array}$ & $\begin{array}{l}\text { 1. Membuat sistem yang dapat } \\
\text { mempercepat pendataan } \\
\text { sehingga tidak membutuhkan } \\
\text { waktu yang lama dalam } \\
\text { pengerjaannya. } \\
\text { 2. Membuat sistem yang dapat } \\
\text { mencetak laporan dengan } \\
\text { cepat dan akurat tanpa } \\
\text { memerlukan waktu yang lama. }\end{array}$ \\
\hline 2. & Kepala & Menyetujui dan memberikan cicilan tanpa & Membuat \\
\hline
\end{tabular}




\begin{tabular}{|c|c|c|c|}
\hline & Bimbel & $\begin{array}{l}\text { melihat kemampuan wali siswa dan } \\
\text { ekonomi sehingga menyebabkan } \\
\text { pemberian cicilan ke orang tua siswa } \\
\text { tidak sesuai targetnya. }\end{array}$ & $\begin{array}{l}\text { menentukan kelayakan pemberian } \\
\text { cicilan ke orang tua siswa. }\end{array}$ \\
\hline 3. & Wali Siswa & $\begin{array}{l}\text { Wali siswa sering mengalami } \\
\text { penunggakan dan merasakan keraguan } \\
\text { jika ingin mengajukan permohonan } \\
\text { cicilan dikarenakan layak atau tidaknya } \\
\text { permohonan cicilan akan diterima oleh } \\
\text { bimbel. }\end{array}$ & $\begin{array}{l}\text { Membuat sistem dengan form } \\
\text { permohonan cicilan } \\
\text { didalamnya ada beberapa kriteria } \\
\text { yang dapat disesuaikan dengan } \\
\text { wali siswa sehingga dapat } \\
\text { menunjang hasil keputusan } \\
\text { penentuan kelayakan. }\end{array}$ \\
\hline
\end{tabular}

\section{HASIL DAN PEMBAHASAN}

Dari analisa permasalahan yang disebutkan, maka penulis menawarkan sebuah rancangan sistem yang dapat mempercepat pendataan sehingga tidak membutuhkan waktu yang lama dalam pengerjaannya, menentukan kelayakan pemberian cicilan ke orang tua siswa agar menjadi lebih akurat, mencetak laporan dengan cepat dan tepat tanpa memerlukan waktu yang lama dengan menggunakan metode perhitungan Simple Additive Weighting (SAW) yaitu metode penjumlahan terbobot dari rating kinerja yang ada pada setiap alternatif dalam semua atribut (Darmastuti, 2013). Adapun rumus yang digunakan pada metode Simple Additive Weighting yaitu:

Vi : Nilai akhir alternatif

$$
V_{i}=\sum_{i=1}^{n} W_{j} r_{i j}
$$

$\mathrm{Wj}$ : Bobot yang telah ditentukan

rij : Normalisasi matriks

Langkah untuk menyelesaikan masalah dengan metode SAW (Abadi \& Latifah, 2016) adalah sebagai berikut:

1) Menentukan kriteria-kriteria (penghasilan wali, tanggungan wali, usia dan status rumah)

Tabel 4. Kriteria

\begin{tabular}{|c|c|c|}
\hline Kriteria & Kode & Keterangan \\
\hline Penghasilan Wali & C1 & Benefit \\
\hline Tanggungan Wali & C2 & Benefit \\
\hline Usia & C3 & Benefit \\
\hline Status Rumah & C4 & Benefit \\
\hline
\end{tabular}

2) Menetapkan rating untuk kecocokan di setiap alternatif pada kriteria.

Tabel 5. Kriteria Penghasilan Wali

\begin{tabular}{|c|c|c|}
\hline Kriteria & Kriteria Pemohon & Nilai Crisp \\
\hline \multirow{3}{*}{$\begin{array}{c}\text { Penghasilan Wali } \\
\text { (C1) }\end{array}$} & $<=1$ juta & 25 \\
\cline { 2 - 3 } & 1 juta -2 juta & 50 \\
\cline { 2 - 3 } & 2 juta -5 juta & 75 \\
\cline { 2 - 3 } & $>5$ juta & 100 \\
\hline
\end{tabular}

Tabel 6. Kriteria Tanggungan Wali

\begin{tabular}{|c|c|c|}
\hline Kriteria & Kriteria Pemohon & Nilai Crisp \\
\hline \multirow{2}{*}{$\begin{array}{c}\text { Tanggungan Wali } \\
\text { (C2) }\end{array}$} & $>5$ orang & 25 \\
\cline { 2 - 3 } & 3 orang -5 orang & 50 \\
\cline { 2 - 3 } & 2 orang & 75 \\
\cline { 2 - 3 } & 1 orang & 100 \\
\hline
\end{tabular}

Tabel 7. Kriteria Usia

\begin{tabular}{|c|c|c|}
\hline Kriteria & Kriteria Pemohon & Nilai Crisp \\
\hline \multirow{3}{*}{\begin{tabular}{c} 
Usia \\
\multirow{2}{*}{$(\mathrm{C} 3)$}
\end{tabular}} & $>50$ tahun & 25 \\
\cline { 2 - 3 } & $41-50$ tahun & 50 \\
\cline { 2 - 3 } & $30-40$ tahun & 75 \\
\cline { 2 - 3 } & $<30$ tahun & 100 \\
\hline
\end{tabular}


Tabel 8. Kriteria Status Rumah

\begin{tabular}{|c|c|c|}
\hline Kriteria & Kriteria Pemohon & Nilai Crisp \\
\hline \multirow{3}{*}{$\begin{array}{c}\text { Status Rumah } \\
\text { (C4) }\end{array}$} & Kost/Kontrak & 25 \\
\cline { 2 - 3 } & Rumah Orang Tua & 50 \\
\cline { 2 - 3 } & Rumah Dinas & 75 \\
\cline { 2 - 3 } & Rumah Sendiri & 100 \\
\hline
\end{tabular}

3) Mengkonversi alternatif pada setiap kriteria ke dalam nilai crisp.

Tabel 9. Nilai Awal

\begin{tabular}{|c|c|c|c|c|}
\hline Nama & C1 & C2 & C3 & C4 \\
\hline Fahri & 25 & 75 & 50 & 100 \\
\hline Deana & 100 & 100 & 75 & 50 \\
\hline Ronald & 75 & 75 & 75 & 50 \\
\hline Listiana & 75 & 50 & 100 & 75 \\
\hline Damar & 100 & 25 & 100 & 100 \\
\hline
\end{tabular}

4) Matriks Kriteria

5) Normalisasi Matriks

$$
X=\left[\begin{array}{cccc}
25 & 75 & 50 & 100 \\
100 & 100 & 75 & 50 \\
75 & 75 & 75 & 50 \\
75 & 50 & 100 & 75 \\
100 & 25 & 100 & 100
\end{array}\right]
$$

Menghitung nilai peringkat ternormalisasi (rij) dari alternatif $\mathrm{Ai}$ pada atribut $\mathrm{Cj}$ berdasarkan persamaan yang disesuaikan dengan jenis atributnya.

$$
\begin{aligned}
& \mathrm{R}_{11}=\frac{25}{\max (25,100,75,75,100)}=\frac{25}{100}=0,25 \\
& \mathrm{R}_{12}=\frac{100}{\max (25,100,75,75,100)}=\frac{100}{100}=1 \\
& \mathrm{R}_{13}=\frac{75}{\max (25,100,75,75,100)}=\frac{75}{100}=0,75 \\
& \mathrm{R}_{14}=\frac{75}{\max (25,100,75,75,100)}=\frac{75}{100}=0,75 \\
& \mathrm{R}_{15}=\frac{100}{\max (25,100,75,75,100)}=\frac{100}{100}=1 \\
& \mathrm{R}_{21}=\frac{75}{\max (75,100,75,50,25)}=\frac{75}{100}=0,75 \\
& \mathrm{R}_{22}=\frac{100}{\max (75,100,75,50,25)}=\frac{100}{100}=1 \\
& \mathrm{R}_{23}=\frac{75}{\max (75,100,75,50,25)}=\frac{75}{100}=0,75 \\
& \mathrm{R}_{24}=\frac{50}{\max (75,100,75,50,25)}=\frac{50}{100}=0,5 \\
& \mathrm{R}_{25}=\frac{25}{\max (75,100,75,50,25)}=\frac{25}{100}=0,25 \\
& \mathrm{R}_{31}=\frac{50}{\max (50,75,75,100,100)}=\frac{50}{100}=0,5 \\
& \mathrm{R}_{31}=\frac{50}{\max (50,75,75,100,100)}=\frac{50}{100}=0,5 \\
& \mathrm{R}_{32}=\frac{75}{\max (50,75,75,100,100)}=\frac{75}{100}=0,75 \\
& \mathrm{R}_{33}=\frac{75}{\max (50,75,75,100,100)}=\frac{75}{100}=0,75 \\
& \mathrm{R}_{34}=\frac{100}{\max (50,75,75,100,100)}=\frac{100}{100}=1 \\
& \mathrm{R}_{35}=\frac{100}{\max (50,75,75,100,100)}=\frac{100}{100}=1 \\
& \mathrm{R}_{41}=\frac{100}{\max (100,50,50,75,100)}=\frac{100}{100}=1 \\
& \mathrm{R}_{42}=\frac{50}{\max (100,50,50,75,100)}=\frac{50}{100}=0,5 \\
& \mathrm{R}_{43}=\frac{50}{\max (100,50,50,75,100)}=\frac{50}{100}=0,5 \\
& \mathrm{R}_{44}=\frac{75}{\max (100,50,50,75,100)}=\frac{75}{100}=0,75 \\
& \mathrm{R}_{45}=\frac{100}{\max (100,50,50,75,100)}=\frac{100}{100}=1
\end{aligned}
$$


Maka didapatkan matriks $\mathrm{R}$ yaitu sebagai berikut:

$$
\mathrm{R}=\left(\begin{array}{cccc}
0,25 & 0,75 & 0,5 & 1 \\
1 & 1 & 0,75 & 0,5 \\
0,75 & 0,75 & 0,75 & 0,5 \\
0,75 & 0,5 & 1 & 0,75 \\
1 & 0,25 & 1 & 1
\end{array}\right)
$$

6) Untuk mendapatkan hasil penilaian, matriks $\mathrm{R}$ dikalikan dengan nilai $\mathrm{W}$, sehingga diperoleh :

$$
\mathrm{V}_{1}=(30 * 0,25)+(20 * 0,75)+(25 * 0,5)+(25 * 1)=60
$$

$\mathrm{V}_{2}=(30 * 1)+(20 * 1)+(25 * 0,75)+(25 * 0,5)=81$

$\mathrm{V}_{3}=(30 * 0,75)+(20 * 0,75)+(25 * 0,75)+(25 * 0,5)=69$

$\mathrm{V}_{4}=(30 * 0,75)+(20 * 0,5)+(25 * 1)+(25 * 0,75)=76$

$\mathrm{V}_{5}=(30 * 1)+(20 * 0,25)+(25 * 1)+(25 * 1)=85$

Tabel 10. Penilaian Kelayakan

\begin{tabular}{|c|c|c|c|c|c|c|}
\hline Nama & C1 & C2 & C3 & C4 & V & Hasil \\
\hline Fahri & 25 & 75 & 50 & 100 & 60 & Tidak Layak \\
\hline Deana & 100 & 100 & 75 & 50 & 81 & Layak \\
\hline Ronald & 75 & 75 & 75 & 50 & 69 & Tidak Layak \\
\hline Listiana & 75 & 50 & 100 & 75 & 76 & Layak \\
\hline Damar & 100 & 25 & 100 & 100 & 85 & Layak \\
\hline
\end{tabular}

Dari hasil di atas, Damar memiliki nilai yang paling tinggi yaitu 85. Maka Damar menjadi yang paling layak mendapat cicilan karena untuk mendapat kelayakan berada di kerentangan nilai 71100 .

\section{Flowchart Proses Perhitungan}

Flowchart merupakan simbol-simbol dalam pekerjaan yang menunjukan bagan aliran proses yang saling bekerja sama (Noor \& Masykurinnisa, 2017).

Berikut adalah perancangan menggunakan flowchart proses perhitungan kelayakan penerima cicilan:

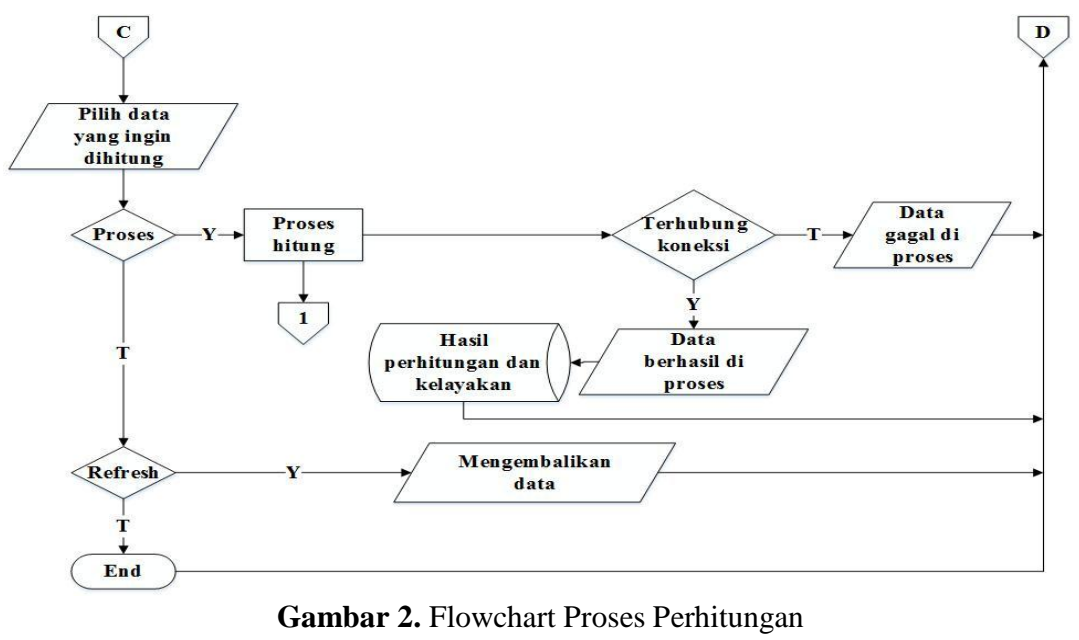

Pada gambar 3 terdapat flowchart proses perhitungan dimana menunjukan alur perhitungan untuk menentukan kelayakan penerima cicilan

\section{Pseudocode Proses Perhitungan}

begin

pilih data yang ingin dihitung

$I f($ pilih $=$ proses $)$ then

proses (hitung)

begin

if(conn=hitung) then

data berhasil diproses

else 
data gagal diproses

end

begin

if(pilih=refresh) then

proses refresh

else

keluar

end

\section{Tampilan Layar}

Berikut ini adalah tampilan layar yang ada pada sistem penunjang keputusan pembayaran sumbangan pembinaan pendidikan dengan cicilan:

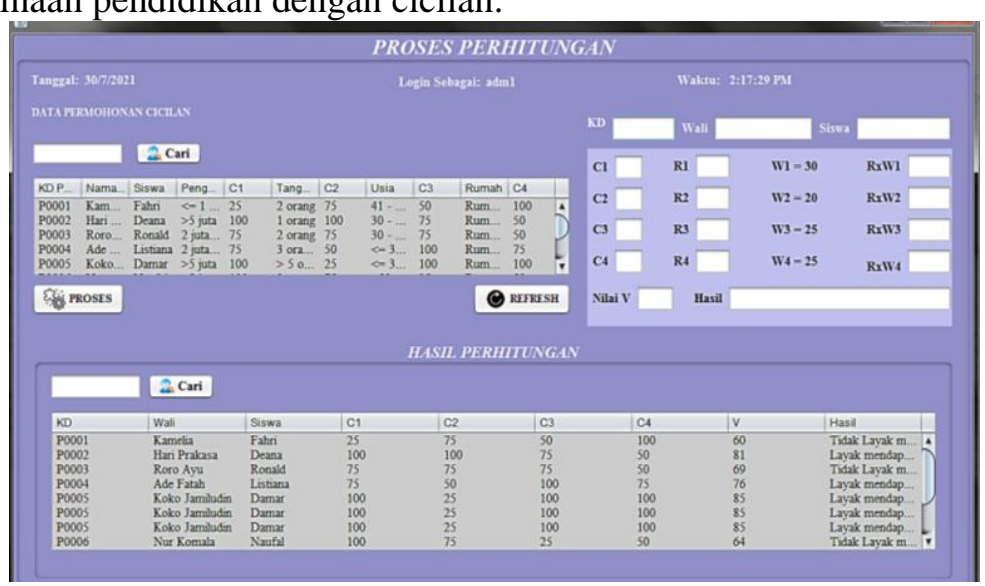

Gambar 3. Tampilan Layar Proses Perhitungan

Pada gambar 4 tampilan layar proses perhitungan dimana proses untuk menghitung kelayakan penerima cicilan dengan menekan button proses yang datanya akan langsung tersimpan pada database.

\begin{tabular}{|c|c|c|c|c|c|c|c|c|}
\hline \multicolumn{8}{|c|}{$\begin{array}{c}\text { BIMBINGAN BELAJAR } \\
\text { BINTANG CEMERLANG } \\
\text { JL. Trikora I RT } 007 \text { RW } 09 \text { Ked Gedong Pasar Rebo Jakarta Timur }\end{array}$} & \\
\hline \multicolumn{9}{|c|}{ LAPORAN DATA HASIL PERHITUNGAN } \\
\hline KD & Nama Wali & Nama Siswa & $\mathrm{Cl}$ & $\mathrm{C} 2$ & $\mathrm{C} 3$ & $\mathrm{C} 4$ & $\mathrm{v}$ & Hasil Kelayakan \\
\hline P0001 & Kamelia & Fahri & 25 & 75 & 50 & 100 & 60 & Tidak Layak mendapat cicilan \\
\hline P0002 & Hari Prakasa & Deana & 100 & 100 & 75 & 50 & 81 & Layak mendapat cicilan \\
\hline P0003 & Roro Ayu & Ronald & 75 & 75 & 75 & 50 & 69 & Tidak Layak mendapat cicilan \\
\hline P0004 & Ade Fatah & Listiana & 75 & 50 & 100 & 75 & 76 & Layak mendapat cicilan \\
\hline P0005 & Koko Jamiludin & Damar & 100 & 25 & 100 & 100 & 85 & Layak mendapat cicilan \\
\hline P0006 & Nur Komala & Naufal & 100 & 75 & 25 & 50 & 64 & Tidak Layak mendapat cicilan \\
\hline
\end{tabular}

Gambar 4. Laporan Hasil Perhitungan

Pada gambar 5 laporan hasil perhitungan adalah bukti perhitungan yang sebelumnya sudah di proses kelayakannya menjadi lebih tepat dan akurat. 


\section{SIMPULAN}

Dilihat dari permasalahan pembayaran, penulis membuat sebuah sistem dengan rancangan flowchart yang sesuai dengan solusi yang diinginkan yaitu pendataan menjadi lebih cepat, mengambil keputusan menjadi lebih akurat dan pembuatan laporan menjadi lebih cepat dan tepat dimana untuk membuat sistem penunjang keputusan pembayaran sumbangan pembinaan pendidikan dengan cicilan digunakan Simple Additive Weighting (SAW) dengan komponen penghasilan wali siswa, jumlah anak, usia dan status rumah. Sistem ini kemudian dibangun dengan tools Netbeans IDE 8.2 sehingga tujuan penelitian ini dapat tercapai.

\section{DAFTAR PUSTAKA}

[1] Abadi, S., \& Latifah, F. (2016). Decision Support System Penilaian Kinerja Karyawan Pada Perusahaan Menggunakan Metode Simple Additive Weighting. Jurnal TAM (Technology Acceptance Model), 6, 37-43.

http://ojs.stmikpringsewu.ac.id/index.php/JurnalTam/article/view/59

[2] Andalia, F. (2015). Pengembangan Sistem Informasi Pengolahan Data Padang Teknik Informatika. Jurnal Ilmiah Komputer dan Informatika (KOMPUTA), 4(2), 190-201. https://ojs.unikom.ac.id/index.php/komputa/article/view/2431

[3] Andryanto, T., \& Aruan, M. C. (2021). Aplikasi Sistem Penilaian Penggajian Santri Pada Remaja

[4] Masjid Al-Ikhlas Berbasis Java Netbeans. Semnas Ristek (Seminar Nasional Riset Dan Inovasi Teknologi), 5(1), 726-732.

http://www.proceeding.unindra.ac.id/index.php/semnasristek/article/view/4987

[5] Anjani, T., \& Mutia, I. (2020). Perancangan Aplikasi Peminjaman Buku Perpustakaan Pada SDN Mekarjaya 11 Depok. STRING (Satuan Tulisan Riset Dan Inovasi Teknologi), 5(1). https://journal.lppmunindra.ac.id/index.php/STRING/article/view/4883

[6] Darmastuti, D. (2013). Implementasi Metode Simple Additive Weighting ( SAW ) Dalam Sistem Informasi Lowongan Kerja Berbasis Web Untuk Rekomendasi Pencari Kerja Terbaik. Jurnal Sistem Dan Teknologi Informasi, 16(2), 1-6.

http://jurnal.untan.ac.id/index.php/justin/article/view/2658

[7] Hardiyanti, T. (2016). Sistem Pendukung Keputusan untuk Menentukan Biaya Sumbangan Penyelenggaraan Pendidikan bagi Siswa Baru dengan Menggunakan Metode Simple Additive Weighting pada SMK St . Fransiskus Semarang. JOINS (Journal of Information System) Udinus, 78-89. http://publikasi.dinus.ac.id/index.php/joins/article/view/1178

[8] [Noor, M., \& Masykurinnisa, A. (2017). Aplikasi Ayatul Ahkam Berbasis Web. Jurnal Sains Dan Informatika, 3(2), 94-100. https://doi.org/10.34128/jsi.v3i2.107

[9] Prabowo, E., \& Suyono, S. (2018). Perancangan Aplikasi Sistem Informasi Pembayaran Sekolah Menggunakan Visual Basic ( Studi Kasus MTS Guppi Airnaningan ). Konferensi Mahasiswa Sistem Informasi, 6(1), 69-75.

http://ojs.stmikpringsewu.ac.id/index.php/procidingkmsi/article/view/622

[10] Sihombing, M. M. (2021). Peningkatan Kualitas Pendidikan Anak Melalui Bimbingan Belajar Yang Dilakukan Di Puri Cempaka. Jurnal pkm, 1(1), 7-13.

http://journal.sttdp.ac.id/index.php/sttdp/article/view/65

[11] Siti Aisyah. (2019). Aplikasi Sistem Pendukung Keputusan Analisis Kelayakan Pemberian Kredit Menggunakan Metode SAW Pada Perusahaan Leasing. Jurnal TEKNOVASI, 6 (3), 255-264. https://www.ejurnal.plm.ac.id/index.php/Teknovasi/article/view/303 